\title{
A practical heat of hydration model for concrete curing for geotechnical applications
}

Ryan Yin Wai Liu MEng, ACGI, AFHEA

Department of Civil and Environmental Engineering, Imperial College London, London, UK (Orcid:0000-0002-5278-6426) (corresponding author: ryl13@ic.ac.uk)

David M. G. Taborda MEng, PhD, DIC

Department of Civil and Environmental Engineering, Imperial College London, London, UK (Orcid:0000-0001-5391-2087)
Anthony Fisher MEng, CEng, MICE

Cementation Skanska, UK

Peter J. Bourne-Webb MSc, PhD, DIC, CEng, MICE, CMEngNZ CERIS, Instituto Superior Técnico, ULisboa, Lisbon, Portugal (Orcid:00000003-1203-4710)

Thermal integrity profiling (TIP) is a common non-destructive technique to evaluate the quality of construction of piles by analysing the temperature fields due to heat of hydration from freshly cast concrete piles. For this process to be accurate, a reliable concrete heat of hydration model is required. This paper proposes a practical and simple technique to calibrate a four-parameter model for the prediction of concrete heat of hydration. This model has been shown to be able to reproduce the evolution of heat of hydration measured in laboratory tests, as well as field measurements of temperature within curing concrete piles, as part of a TIP operation performed at a site in London. With the simplicity of the model and the small number of model parameters involved, this model can be easily and quickly calibrated, enabling quick predictions of expected temperatures for subsequent casts using the same concrete mix.

Keywords: concrete heat of hydration/geotechnical engineering/piles/thermal integrity profiling

\section{Notation}

D pile diameter

$E_{\mathrm{a}} \quad$ activation energy

$k \quad$ reaction constant

$n \quad$ order of reaction

$n_{\mathrm{r}} \quad$ number of radial discretisation in the numerical tool

$n_{\theta} \quad$ number of angular discretisation in the numerical tool

$n^{*} \quad$ time-dependent function within the heat of hydration model

$P \quad$ heat of hydration power per unit volume of concrete

$P_{\text {ref }} \quad$ reference heat of hydration power per unit volume of concrete

$Q_{\text {acc }} \quad$ accumulated heat of hydration

$Q_{\max } \quad$ heat of hydration model parameter

$Q_{\text {ref }} \quad$ reference accumulated heat of hydration

$q \quad$ heat flux

$R \quad$ universal gas constant

$r \quad$ radial distance

$T$ temperature

$T_{\text {ref }} \quad$ reference temperature

$t \quad$ time

$t_{\mathrm{n}} \quad$ cut-off value for determining $n^{*}(t)$

$X_{\text {rand }}$ random number

$\alpha \quad$ thermal diffusivity

$\beta \quad$ heat of hydration model parameter

$\Delta \quad$ mutation factor

$\Delta_{\max } \quad$ maximum mutation factor

$\Delta T \quad$ change in temperature

$\theta \quad$ angular coordinate

$\lambda \quad$ thermal conductivity
$\rho_{\text {concrete }}$
$\tau \quad$ heat of hydration model parameter
mass of cement per unit mass of concrete

\section{Introduction}

The heat of hydration of concrete refers to the heat that is released from the exothermic reaction between cement and water when concrete is mixed. Being a very versatile material, concrete is commonly used in the construction of geotechnical structures, such as piles, retaining walls, tunnel linings and so on. As a result of the heat of hydration, together with the insulating effect from the surrounding soil due to its relatively low thermal conductivity, high temperatures can build up within freshly cast concrete. This is evident, for instance, in thermal integrity profiling (TIP) operations. TIP is a non-destructive technique for evaluating the post-construction integrity of piles, which consists of interpreting the measured temperatures over the depth of a pile during its casting and subsequent hydration, in order to identify potential anomalies in the structure. When coupled with a heat of hydration model, a back-analysis of the measured temperature variation can provide an estimate of the variation with depth of the actual pile diameter. As an example, a temperature of $63^{\circ} \mathrm{C}$ (i.e. about $50^{\circ} \mathrm{C}$ above ambient temperature) was measured at the reinforcing cage of a $1.2 \mathrm{~m}$ dia. pile (Johnson, 2016), with the temperatures at the centre of the pile expected to be even higher. Due to the high temperatures and thermal gradients developing within the concrete, thermal stresses and strains are induced, which can lead to the development of thermal cracks. For instance, concrete thermal cracking was observed on the inner face of a $100 \mathrm{~m}$ dia., $2.8 \mathrm{~m}$ thick and $119 \mathrm{~m}$ deep cylindrical, cast-in-place diaphragm 
wall in Japan (Liou, 1999), with the thermal stress resulting from the hydration of concrete being deemed as important as the soil and water pressures acting on the outside of the wall. Moreover, with geotechnical concrete structures becoming increasingly massive in modern infrastructure, higher temperatures and thermal gradients are anticipated, and thus any associated undesirable effects. It is, therefore, increasingly important to be able to characterise accurately the temperature fields resulting from the heat of hydration.

There are sophisticated heat of hydration models for concrete available in the literature (e.g. Kishi and Maekawa, 1995, 1997; Swaddiwudhipong et al., 2002) which have been shown to be able to model the evolution of heat of hydration accurately by accounting for the cement reaction kinetics. However, these models involve a large number of parameters, which can only be determined by knowing the detailed cement composition and properties (e.g. content of each cement phase, cement fineness, water-to-cement ratio $(w / c)$, content and properties of any admixtures added), many of which are not readily available in practical geotechnical applications. As an alternative, a popular and simpler general heat of hydration model was presented by Schindler and Folliard (2005), which involves far fewer model parameters, and makes use of the 'equivalent age' concept (which is also known as 'equivalent maturity') to account for the effects of temperature on the rate of hydration. Based on similar principles, an alternative approach is proposed in this paper, whereby the temperature dependence of the heat of hydration is formulated using fundamental laws of chemistry, thus avoiding the use of the 'equivalent age' concept and enabling a further simplification of the model. This means that knowledge of only the main characteristics of the concrete mix is required for quick predictions of temperature fields associated with the heat of hydration. Moreover, the simplicity of the model and of the corresponding calibration procedure means it can be readily applied in the context of thermal integrity testing of geotechnical structures and, when coupled with thermo-mechanical modelling in the prediction of thermally induced cracking of concrete.

\section{Formulation of the heat of hydration model}

Fundamentally, a heat of hydration model consists of a set of relationships that can be used to predict a heat flux per unit volume $\left[(\mathrm{J} / \mathrm{s}) / \mathrm{m}^{3}\right]$ (also denoted as 'power' in this paper). Clearly, the phenomena taking place during hydration are very complex and depend on a wide range of factors, which are considered explicitly by more sophisticated models, such as those proposed by Kishi and Maekawa $(1995,1997)$ and Swaddiwudhipong et al. (2002). However, it is unlikely that each of these factors will all have identical impact on the heat given out by the hydrating concrete, which means that the formulation of a practical model to simulate this phenomenon needs to focus on including those that are known to be the most influential. In effect, according to Odler (1998), the amount and rate of hydration heat liberation are mainly affected by the following factors.
- Cement composition: the total amount of heat given out at the end of hydration and the rate of hydration at early ages are dependent on the proportions of constituents within the cement. For example, cements with higher contents of tricalcium silicate $\left(\mathrm{C}_{3} \mathrm{~S}\right)$ and tricalcium aluminate $\left(\mathrm{C}_{3} \mathrm{~A}\right)$ generate more heat and at higher rates (Portland Cement Association, 1997).

- Cement fineness: a higher cement fineness means a larger surface area for reaction with water and, therefore, higher rate of hydration at early ages (Bentz et al., 1999; Portland Cement Association, 1997; Schindler and Folliard, 2005; Sedaghat et al., 2015). However, the total amount of heat given out at the end of hydration is not affected (Bentz et al., 1999; Portland Cement Association, 1997).

- Curing temperature: the rate of hydration at early ages increases with the increasing curing temperature, but the total amount of heat given out at the end of hydration appears to be unaffected (Carlson and Forbrich, 1938). Copeland et al.

(1960) suggested that the dependence of rate of hydration on curing temperature is related to the Arrhenius equation, which is an equation in physical chemistry that describes the dependence of reaction rates on temperature.

- $w / c$ : incomplete hydration occurs if there is an insufficient amount of water to sustain the hydration reaction; this reduces the amount of hydration heat released. Bentz et al. (2009) conducted heat of hydration experiments and showed that the influence of $w / c$ on heat of hydration becomes negligible for values of $w / c$ above 0.425 .

- Presence of any admixtures: for example, the use of fly ash reduces both the total amount of heat given out at the end of hydration, as well as the rate of hydration (Portland Cement Association, 1997).

The starting point of the model is to use an S-shaped curve (Equation 1) to describe the 'reference' accumulated heat of hydration per unit mass of cement with time (van Breugel, 1991), which is then corrected using simple relationships - to mimic the various factors listed above.

1.

$$
Q_{\mathrm{ref}}(t)=Q_{\max } e^{-\left(\frac{\tau}{t}\right)^{\beta}}
$$

In Equation 1, $Q_{\text {ref }}(t)\left[\mathrm{J} / \mathrm{kg}_{\text {cement }}\right]$ is the reference accumulated heat of hydration released up to an age of $t[\mathrm{~s}]$, and $Q_{\max }\left[\mathrm{J} / \mathrm{kg}_{\text {cement }}\right]$, $\tau[\mathrm{s}]$ and $\beta[-]$ are model parameters to be calibrated. Note that the designation 'reference' is used for $Q_{\text {ref }}$ because the effects of temperature on the rate of hydration are not considered, and therefore it represents the accumulated heat of hydration up to an age $t$ when the curing process takes place under isothermal conditions (i.e. at a constant reference temperature, $T_{\text {ref }}[\mathrm{K}]$, which is the temperature at which $Q_{\max }, \tau$ and $\beta$ are calibrated).

By differentiating Equation 1 with respect to time and multiplying it by the mass of cement per unit volume of concrete, a reference power per unit volume of concrete can be obtained: 


$$
P_{\text {ref }}(t)=\chi \rho_{\text {concrete }} \frac{d Q_{\text {ref }}}{d t}
$$

2.

$$
=\frac{Q_{\max }}{t}\left(\frac{\tau}{t}\right)^{\beta} \beta e^{-\left(\frac{\tau}{t}\right)^{\beta}} \chi \rho_{\text {concrete }}
$$

where $\chi$ is the mass of cement per unit mass of concrete $\left[\mathrm{kg}_{\text {cement }} / \mathrm{kg}_{\text {concrete }}\right]$ and $\rho_{\text {concrete }}$ is the density of concrete $\left[\mathrm{kg}_{\text {concrete }} / \mathrm{m}^{3}\right]$. Note that Equation 2 gives the reference power, which is the heat flux generated by the hydrating concrete per unit volume under isothermal conditions $\left[(\mathrm{J} / \mathrm{s}) / \mathrm{m}^{3}\right]$.

To account for the effects of temperature on the rate of hydration, the rate law, which governs the rate of a chemical reaction is considered:

\section{3.}

$$
\text { Rate } \left.=k \prod_{i}[\text { Reactant }]_{i}\right]^{n_{i}}
$$

where $\left[\right.$ Reactant $\left._{i}\right]$ is the concentration of reactant $i$ and $n_{i}$ is the corresponding order of reaction. The reaction constant $k[-]$ can be calculated using the Arrhenius equation, which is given by

$$
\text { 4. } k=A e^{-\frac{E_{\mathrm{a}}}{R T}}
$$

where $A$ is a constant [-], $E_{\mathrm{a}}$ is the activation energy [ $\left.\mathrm{J} / \mathrm{mol}\right]$, which controls the sensitivity of reaction rate to temperature, $R$ is the universal gas constant $(8.314(\mathrm{~J} / \mathrm{mol}) / \mathrm{K})$ and $T$ is temperature $[\mathrm{K}]$.

Equations 3 and 4 indicate that the rate of a chemical reaction is dependent on the abundance of reactants and temperature. These two factors are indirectly related since curing at higher temperatures leads to faster rates of reaction and hence, a sharper reduction in the abundance of reactants (i.e. a smaller amount of unhydrated cement) which, according to Equation 3, means a slower reaction. To introduce a measure of the abundance of unhydrated cement, the relationship given by Equation 5 is assumed.

5. $\left.\prod_{i}[\text { Reactant }]_{\mathrm{i}}\right]^{n_{i}} \approx\left(\frac{Q_{\max }-Q_{\mathrm{acc}}(t)}{Q_{\max }}\right)^{n^{*}(t)}$

6. $\therefore$ Rate $=A e^{-\frac{E_{\mathrm{a}}}{R T}}\left(\frac{Q_{\max }-Q_{\mathrm{acc}}(t)}{Q_{\max }}\right)^{n^{*}(t)}$

In Equations 5 and $6, n^{*}(t)$ is a function to be determined [-] and $Q_{\text {acc }}(t)$ is the accumulated heat of hydration per unit mass of cement $\left[\mathrm{J} / \mathrm{kg}_{\text {cement }}\right]$ (i.e. including any effects of temperature on the rate of hydration) and is given by

$$
Q_{\mathrm{acc}}(t)=\frac{1}{\chi \rho_{\text {concrete }}} \int_{0}^{t} P(T, t) d t
$$

By assuming that the rate of cement hydration is directly proportional to the power of heat of hydration, the following relationship can be established:

8. $P(T, t)=A^{\prime} e^{-\frac{E_{a}}{R T}}\left(\frac{Q_{\max }-Q_{\mathrm{acc}}(t)}{Q_{\max }}\right)^{n^{*}(t)}$

where $A^{\prime}$ is a constant $\left[(\mathrm{J} / \mathrm{s}) / \mathrm{m}^{3}\right]$. For the case of reference power (i.e. the concrete cures at a constant reference temperature, $T_{\text {ref }}$ $[\mathrm{K}])$, Equation 8 can be rewritten as

9. $P_{\mathrm{ref}}(t)=A^{\prime} e^{-\frac{E_{\mathrm{a}}}{R T_{\mathrm{ref}}}}\left(\frac{Q_{\mathrm{max}}-Q_{\mathrm{ref}}(t)}{Q_{\max }}\right)^{n^{*}(t)}$

By combining Equations 8 and 9, Equation 10 is obtained, which gives the power of heat of hydration per unit volume of concrete, accounting for the effects of temperature on the rate of hydration.

$$
\text { 10. } P(T, t)=P_{\text {ref }}(t) e^{-\frac{E_{\mathrm{a}}}{R}\left[\frac{1}{T}-\frac{1}{T_{\mathrm{ref}}}\right]}\left(\frac{Q_{\mathrm{max}}-Q_{\mathrm{acc}}(t)}{Q_{\max }-Q_{\mathrm{ref}}(t)}\right)^{n^{*}(t)}
$$

In Equation $10, P_{\mathrm{ref}}(t), Q_{\mathrm{acc}}(t)$ and $Q_{\mathrm{ref}}(t)$ are given by Equations 2 , 7 and 1 , respectively. Note that the activation energy, $E_{\mathrm{a}}$, characterises the whole concrete mixture; hence, it is an apparent activation energy, as the hydration process involves different anhydrous components of the cement with independent chemical reactions (D'Aloia and Chanvillard, 2002). Although D'Aloia and Chanvillard (2002) have shown that the apparent activation energy varies with the degree of hydration, this quantity is assumed to be constant in this model for simplicity. Based on the measurements reported by Thomas (2012), a value of $45000 \mathrm{~J} / \mathrm{mol}$ is adopted for $E_{\mathrm{a}}$. Since it is assumed to be constant, Equation 9 can be further simplified into

11. $P_{\text {ref }}(t)=B\left(\frac{Q_{\max }-Q_{\text {ref }}(t)}{Q_{\max }}\right)^{n^{*}(t)}$

where $B$ is a constant $\left[(\mathrm{J} / \mathrm{s}) / \mathrm{m}^{3}\right]$. Applying natural logarithms on both sides of the equation yields 
12. $\ln P_{\mathrm{ref}}(t)=\ln B+n^{*}(t) \ln \left(1-\frac{Q_{\mathrm{ref}}(t)}{Q_{\max }}\right)$

Clearly, based on the relationship above, $n^{*}(t)$ is determined by the slope of $\ln \left(1-\frac{Q_{\text {ref }}(t)}{Q_{\max }}\right)$ plotted against $\ln P_{\text {ref }}(t)$ and is therefore given by Equation 13 .

13.

$$
\begin{aligned}
& n^{*}(t)=\frac{d \ln P_{\mathrm{ref}}(t)}{d \ln \left(1-\frac{Q_{\mathrm{ref}}(t)}{Q_{\mathrm{max}}}\right)}=\frac{\frac{d \ln P_{\mathrm{ref}}(t)}{d t}}{\frac{d \ln \left(1-\frac{Q_{\mathrm{ref}}(t)}{Q_{\mathrm{max}}}\right)}{d t}} \\
& \Rightarrow n^{*}(t)=\left(e^{\left(\frac{\tau}{t}\right)^{\beta}}-1\right)\left(\left(1+\beta^{-1}\right)\left(\frac{t}{\tau}\right)^{\beta}-1\right)
\end{aligned}
$$

It is important to note that Equation 13 will become illconditioned when $t$ is very small; therefore, it is necessary to impose a cut-off value $t_{n}$ when determining $n^{*}(t)$.

14.

$$
n^{*}\left(t \leq t_{n}\right)=n^{*}\left(t=t_{n}\right)
$$

Based on parametric studies, it has been observed that the value of $t_{n}$ does not have a significant influence on the results, provided that it is sufficiently small. In this paper, a value of $t_{n}=2$ days has been used throughout.

The proposed heat of hydration model can be implemented by using Equations 1, 2, 7, 10 and 13, subjected to the condition given by Equation 14. While the effects of temperature on the rate of hydration have been accounted for in the above equations, the effects of other factors, such as cement composition, cement fineness, $w / c$ of the mixture and the presence of any admixtures, are implicitly dealt with through the calibration of the three model parameters: $Q_{\max }, \tau$ and $\beta$.

\section{Validation with isothermal laboratory tests}

The capabilities of the proposed heat of hydration model are first demonstrated by simulating experimental test results. There are three different types of heat of hydration laboratory tests, depending on the thermal boundary conditions imposed during testing: adiabatic (where no energy loss to the surroundings is allowed from the hydrating concrete), semi-adiabatic (where some energy loss to the surroundings is allowed) and isothermal (where the hydrating concrete is kept at a constant temperature). For the validation of the proposed model, isothermal tests are preferred for two reasons: first, they eliminate the complexity of simulating the heat transfer or a non-linear thermal boundary condition and second, they allow the measurement of the heat of hydration given out by the same concrete mix when cured at different temperatures. According to the formulation of the model introduced in the previous section, in this scenario, the model parameters $\left(Q_{\max }, \tau, \beta\right.$ and $\left.E_{\mathrm{a}}\right)$ should be unique for a given concrete mix, thus allowing the validation of the model component that introduces temperature dependency (i.e. Equation 10).

Two distinct approaches have been typically followed when determining the heat of hydration of cement under isothermal conditions: isothermal conduction calorimetry and heat of solution. According to Sedaghat et al. (2013), the former is characterised by higher precision and has the advantage of measuring heat of hydration immediately after the cement is mixed with water, which is very important as heat generation from the hydration reaction is rapid and significant in the short term. Therefore, the validation of the proposed model is performed using results from isothermal conduction calorimetry tests.

Wadsö (2003) presented the results of tests performed on a cement 'Anläggningscement' (which is classified as CEM I $42.5 \mathrm{BV} / \mathrm{SR} / \mathrm{LA}$ ) at four temperatures: $20,30,40$ and $50^{\circ} \mathrm{C}$. Based on the time plotted against the accumulated heat of hydration curves of the four tests, which are calculated from the time plotted against the heat of hydration power curves presented by Wadsö (2003), and assuming $E_{\mathrm{a}}=45000 \mathrm{~J} / \mathrm{mol}$ (as mentioned in the previous section), the model parameters $Q_{\max }, \tau$ and $\beta$ are calibrated, such that the modelled evolutions of heat of hydration resemble the measured ones. As discussed previously, for a given cement, a unique set of model parameters should be obtained. In the present case, the least squares method was used, leading to $Q_{\max }=$ $333000 \mathrm{~J} / \mathrm{kg}_{\text {cement }}, \tau=68162 \mathrm{~s}$ and $\beta=0.743$ (based on $T_{\text {ref }}=23^{\circ} \mathrm{C}$ ), with the resulting modelled accumulated heat of hydration curves being compared to those obtained experimentally in Figure 1. The close resemblance between the simulated and measured curves demonstrates that the model is capable of reproducing the evolution of heat of hydration with great accuracy, the component of the model establishing

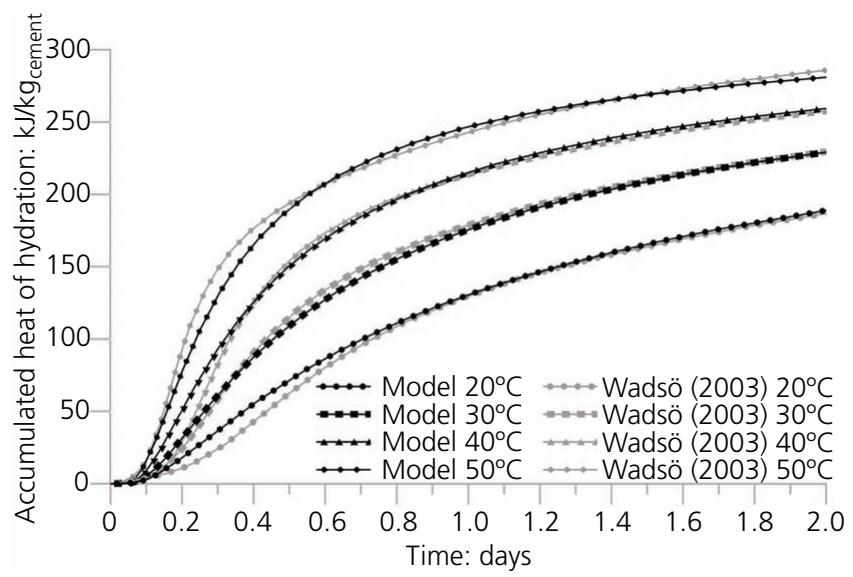

Figure 1. Modelled accumulated heat of hydration curves compared with measured ones from isothermal conduction calorimetry tests by Wadsö (2003) 
the influence of temperature on the heat of hydration (Equation 10) is performing effectively and that the assumption of $E_{\mathrm{a}}=45000 \mathrm{~J} / \mathrm{mol}$ is satisfactory.

Zayed et al. (2013) conducted isothermal conduction calorimetry tests on five ASTM Type II (MH) cements at a temperature of $23^{\circ} \mathrm{C}$, designated as cements $\mathrm{A}, \mathrm{B}, \mathrm{C}, \mathrm{D}$ and $\mathrm{E}$. It is important to note that cement $\mathrm{A}$ was tested at three fineness levels (cement A1, A2 and A3, respectively), while cements $\mathrm{B}$ and $\mathrm{C}$ were tested at two fineness levels (denoted by cement B1, B2, C1 and C2, respectively). This meant that a total of nine ASTM Type II (MH) cement samples were tested (A1, A2, A3, B1, B2, C1, C2, D and E). Note that ASTM Type II cements are moderately sulfate resistant and are widely used in geotechnical applications due to the presence of sulfate in soils. For brevity, only samples from cements A, B and C are used in this paper. As discussed in the section headed 'Formulation of heat of hydration model', the total amount of heat given out at the end of hydration, which is controlled by the model parameter $Q_{\max }$ in the proposed model, is not affected by cement fineness (Bentz et al., 1999; Portland Cement Association, 1997) Therefore, when the model parameters are calibrated, the same $Q_{\max }$ should be adopted for samples from the same cement. The model parameters are again calibrated using the least squares method and are reported in Table 1. Note that both $T_{\text {ref }}=$ $23^{\circ} \mathrm{C}$ and $E_{\mathrm{a}}=45000 \mathrm{~J} / \mathrm{mol}$ are adopted. Figures 2-4 compare the modelled accumulated heat of hydration curves with those measured (Zayed et al., 2013) for cements A, B and C, respectively. Once again, the excellent agreement between the simulated and measured data suggests that the model is capable of reproducing the evolution of heat of hydration with good accuracy using a relatively small number of model parameters.

\section{Validation with field measurements}

To further demonstrate the applicability and accuracy of the model, the complex boundary value problem of a curing concrete pile was simulated. The field data were collected as part of a TIP operation performed at a site in London by Cementation Skanska, during which 14 concrete piles were monitored using distributed fibre optic sensing. As the optical fibres ran along the entire length of the piles, continuous measurements of temperature with depth within the piles were obtained. These were attached to the reinforcement cage of the piles, located at a nominal distance of $75 \mathrm{~mm}$ from the pile edge, and ran down and up each pile three times to measure temperature at six different locations within the

Table 1. Calibrated model parameters for cement samples A1, A2, A3, B1, B2, C1 and C2 from Zayed et al. (2013)

$\begin{array}{lccc}\text { Cement } & Q_{\text {max }}: \mathbf{J} / \mathbf{k g}_{\text {cement }} & \tau: \mathbf{s} & \beta \\ \text { A1 } & 411000 & 76725 & 0.529 \\ \text { A2 } & 411000 & 52349 & 0.573 \\ \text { A3 } & 411000 & 36397 & 0.795 \\ \text { B1 } & 422000 & 57768 & 0.732 \\ \text { B2 } & 422000 & 40984 & 0.856 \\ \text { C1 } & 386000 & 53190 & 0.781 \\ \text { C2 } & 386000 & 40504 & 0.864\end{array}$

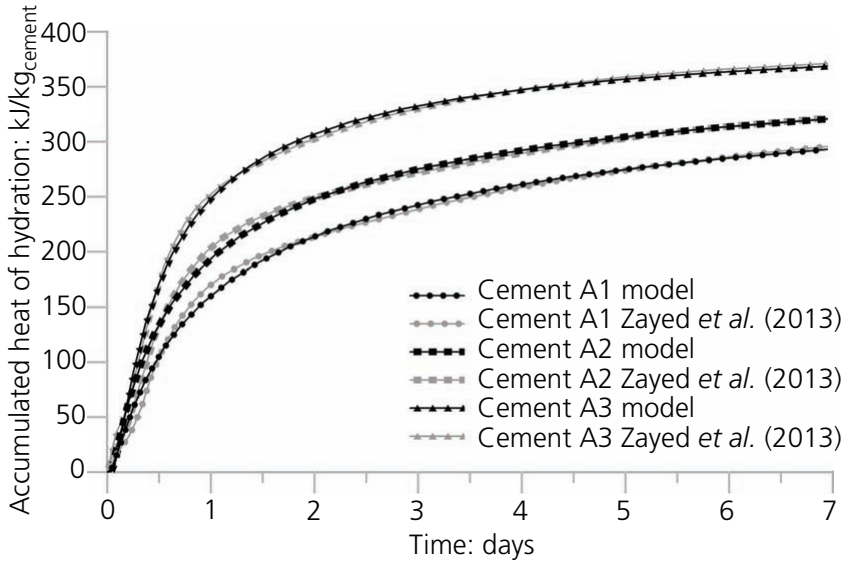

Figure 2. Modelled accumulated heat of hydration curves compared with measured ones (Zayed et al., 2013) for cement A

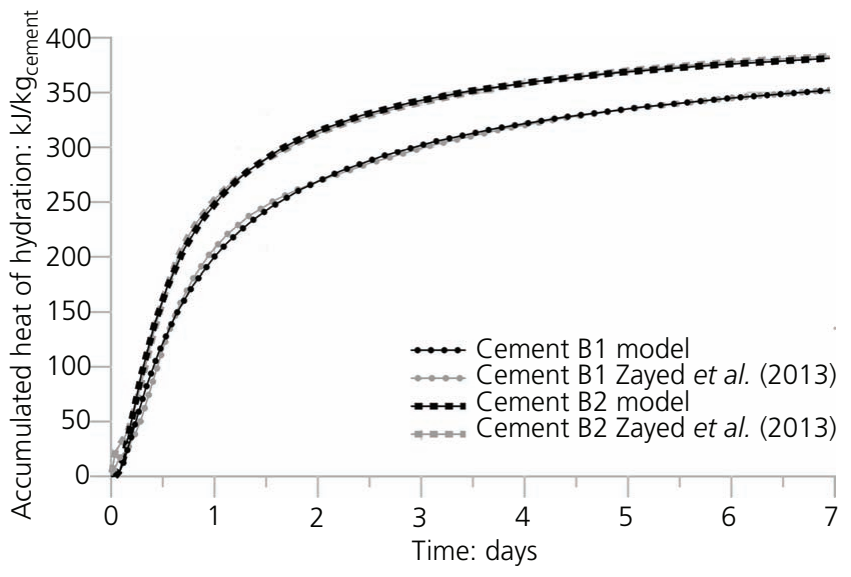

Figure 3. Modelled accumulated heat of hydration curves compared with measured ones (Zayed et al., 2013) for cement B

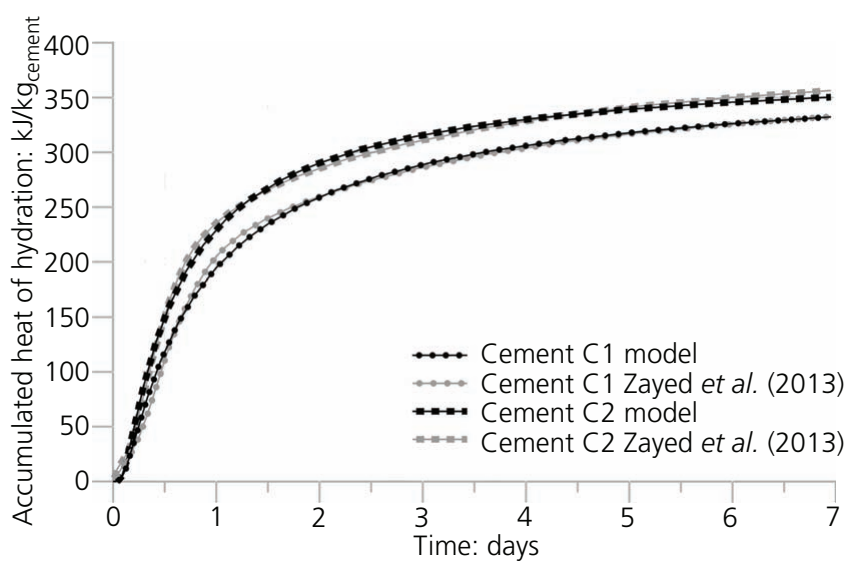

Figure 4. Modelled accumulated heat of hydration curves compared with measured ones (Zayed et al., 2013) for cement $C$ 
cross-section (i.e. spaced at approximately $60^{\circ}$ ). Due to small imprecisions in fibre positions arising from the casting of the pile and the spatial variation of thermal properties of the surrounding ground, a range of temperatures, albeit small, are measured within and along the depth of each pile. As a result, for brevity and clarity, only the median of the temperature measurements that are obtained for the portion of the pile installed within London Clay is considered for each time step, which eventually gives an evolution of median temperature rise with time.

Among the 14 piles measured, a 'test pile', which has a diameter, $D$, of $1.2 \mathrm{~m}$, was cast before the others. To validate the proposed heat of hydration model, the temperature measurements from the test pile were used to calibrate the model parameters; the parameters are subsequently used to model the temperature rise within two other instrumented piles: 'pile $7 \mathrm{a}$ ' $(D=1.8 \mathrm{~m})$ and 'pile 12' $(D=2.4 \mathrm{~m})$. Since the proposed heat of hydration model is non-linear in temperature, it is not possible to assume that the heat of hydration power is constant throughout the pile, as a nonuniform temperature field is expected to develop within the crosssection. To adopt the proposed model to simulate the temperature rise within a boundary value problem (in this case, a curing pile), a numerical technique is required. Naturally, the accuracy of the model is independent of the adopted numerical approach, which can be based on finite differences, finite elements or, in the present case, the superposition of multiple infinite line heat sources (Carslaw and Jaeger, 1959). The adopted technique, which has as its main advantage the fact that it is simple to implement, is outlined in Appendix 1. It is important to note that this numerical technique assumes that the problem is two-dimensional (i.e. the pile is infinitely long), which is a reasonable assumption considering that end effects would not be significant for piles with large length-to-diameter ratios. Moreover, the transfer of heat is assumed to be purely conductive (convective heat transfer due to ground water flow is neglected), as expected for low-permeability soils where groundwater flow is insignificant (Kavanaugh and Rafferty, 2014). Lastly, the adopted methodology implies that the concrete pile and the surrounding soil have the same thermal properties (i.e. thermal conductivity and specific heat capacity). The impact of this assumption has been verified against finite-difference analyses (Sajadi, 2020) and shown to have negligible impact on the predictions when considering typical thermal properties of concrete and soil.

\section{Calibration of model parameters using field measurements of the test pile}

The developed numerical technique (Appendix 1) allows the temperature rise at the radius where the field measurements were taken (i.e. $75 \mathrm{~mm}$ from the pile edge) to be simulated using the proposed heat of hydration model. To calibrate the model parameters $Q_{\max }, \tau$ and $\beta$ ( $E_{\mathrm{a}}=45000 \mathrm{~J} / \mathrm{mol}$ is assumed) such that the simulated temperature rise resembles the median temperature rise measured for the test pile, a genetic algorithm (Azeiteiro et al., 2009; Taborda, 2011) is adopted, which is outlined in Appendix 2. During the calibration process, it is assumed that both the London Clay and the concrete have a volumetric heat capacity of $2148000 \mathrm{~J} /\left(\mathrm{m}^{3} \mathrm{~K}\right)$, which is a reasonable approximation for concrete (see Burg and Ost (1994)), while not being too dissimilar to the values reported by Headon et al. (2009) for London Clay. Similarly, a value of $2.4 \mathrm{~W} /(\mathrm{m} \mathrm{K})$ was chosen for the thermal conductivity of both materials, based on the range of values reported for London Clay by Loveridge et al. (2014) and for concrete by Scanlon and McDonald (1994). The calibration process yielded the following model parameters: $Q_{\max }=220000 \mathrm{~J} / \mathrm{kg}_{\text {cement }}, \tau=$ $85843 \mathrm{~s}$ and $\beta=0.842$ (based on $T_{\text {ref }}=23^{\circ} \mathrm{C}$ and $\chi \rho_{\text {concrete }}=$ $440 \mathrm{~kg}_{\text {cement }} / \mathrm{m}^{3}$ ). Figure 5 shows the comparison between the simulated temperature rise using the calibrated parameters and the median temperature rise from the field measurement for the test pile.

\section{Simulation of temperature rise for pile $7 a$ and pile 12 using test pile calibration and comparisons with field measurements}

As pile $7 \mathrm{a}$ and pile 12 were cast using the same concrete mix as that for the test pile, according to the philosophy of the proposed model, the set of model parameters calibrated from the field measurements of the test pile $\left(Q_{\max }=220000 \mathrm{~J} / \mathrm{kg}_{\text {cement }}, \tau=85843 \mathrm{~s}\right.$ and $\beta=$ 0.842 ) should be applicable to the simulation of temperature fields associated to pile $7 \mathrm{a}$ and pile 12 as well. The same modelling approach as described in the section headed 'Calibration of model parameters using field measurements of the test pile' was used to simulate the temperature rise for pile $7 \mathrm{a}$ and pile 12 , and the results, together with the median temperature rise from the corresponding field measurements, are shown in Figures 6 and 7, respectively.

Clearly, Figures 5-7 indicate that larger piles achieve higher peak temperatures, an aspect that the model has successfully captured. Moreover, the temperature rise for both pile $7 \mathrm{a}$ and pile 12 has been reproduced with a good degree of accuracy; it obtained maximum errors of 12.5 and $8 \%$, respectively. The small errors suggest that the proposed heat of hydration model, together with the adopted modelling approach, is capable of simulating temperature rise due to hydrating concrete when calibrated,

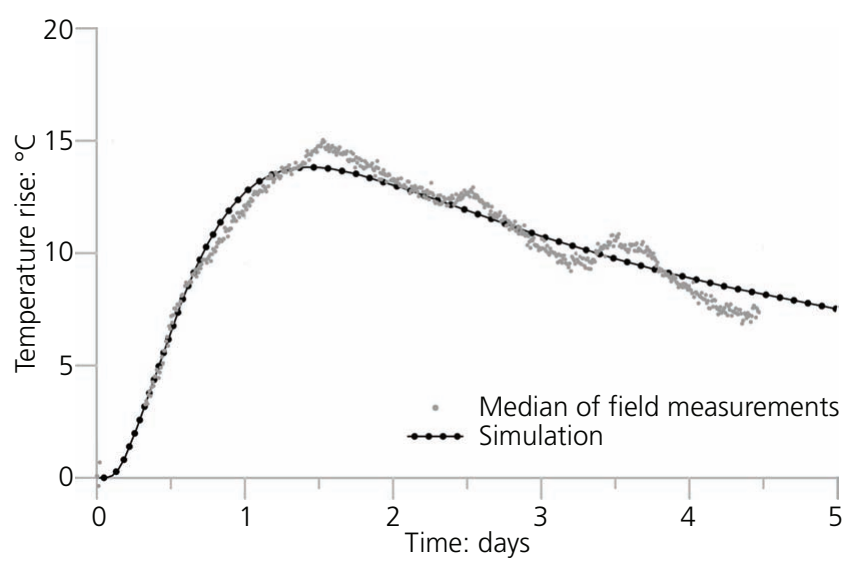

Figure 5. Comparison between the simulated temperature rise using the calibrated parameters and the median temperature rise from the field measurement for the test pile 


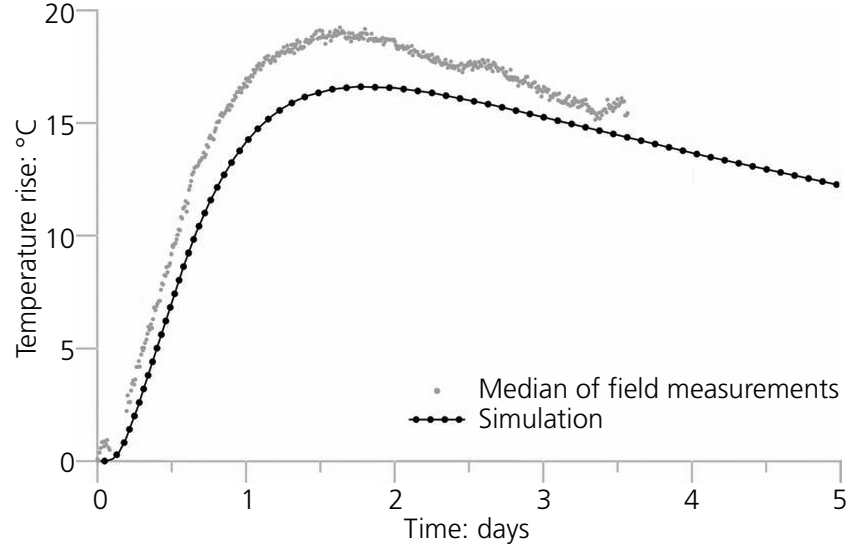

Figure 6. Comparison between the simulated temperature rise using calibrated parameters from test pile and the median temperature rise from the field measurement for pile $7 \mathrm{a}(D=1.8 \mathrm{~m})$

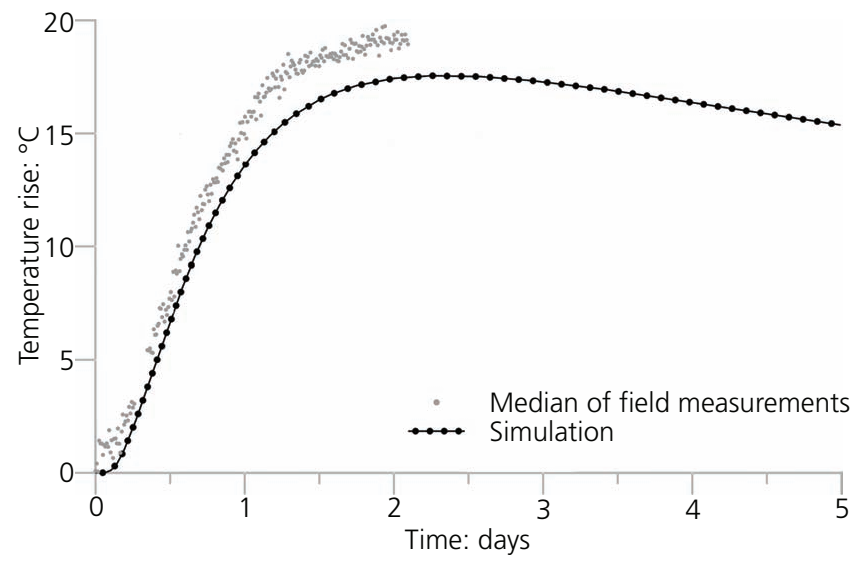

Figure 7. Comparison between the simulated temperature rise using calibrated parameters from test pile and the median temperature rise from the field measurement for pile $12(D=2.4 \mathrm{~m})$

following a systematic and objective approach. This also means that once the model parameters are calibrated and known (the accuracy of which increases with the quantity of field measurements made available for calibration), the developed numerical tool can be adopted to simulate the evolution of temperature field with time of any subsequent casts using the same concrete mix

\section{Conclusions}

A simple heat of hydration model for concrete has been proposed in this paper, with only four parameters requiring calibration $Q_{\max }, \tau, \beta$ and $E_{\mathrm{a}}$. The model has been validated to be able to simulate the evolution of heat of hydration accurately, using both isothermal heat of hydration laboratory test results and field measurements of temperature rise within curing concrete piles. The temperature-dependency component of the model has also been validated by considering heat of hydration tests on the same cement but at different isothermal temperatures. To adopt the model to simulate the temperature rise from a hydrating concrete pile, a numerical tool has been developed, which consists of discretising the pile into infinite line sources (ILSs). This numerical technique, together with the use of genetic algorithms, allows model parameters to be back-calculated from field measurements of temperature rise within the hydrating concrete piles in an objective and efficient way. As soon as the model parameters are calibrated, the numerical tool allows the simulation of the evolution of temperature field with time of any subsequent casts involving the same concrete mix. The success of this numerical technique in the simulation of a hydrating pile by discretising it into ILSs suggests that a similar numerical tool can be developed for predicting temperature fields due to the hydration of concrete for structures of arbitrary shapes, provided that the two-dimensional assumption holds. However, further research and field measurements are required to confirm such a hypothesis.

\section{Acknowledgements}

The first author is funded by the Imperial College President's PhD Scholarship and the Engineering and Physical Sciences Research Council (EPSRC) (grant number: EP/R512540/1). The authors are grateful to Cementation Skanska for kindly providing their TIP measurements for the validation of the proposed model.

\section{Appendix 1}

\section{A numerical technique to simulate temperature rise within a curing concrete pile}

To simulate the temperature rise within a curing concrete pile using the proposed heat of hydration model, taking into account of the non-uniform temperature field within the pile, a numerical technique was developed. In this numerical technique, the crosssection of the pile is discretised radially and angularly into sections, such that the power of heat of hydration from each section is represented by an ILS (see Carslaw and Jaeger (1959)) positioned at the middle of the corresponding section. This is illustrated in Figure 8 for the case where a radial discretisation of $n_{\mathrm{r}}=5$ and an angular discretisation of $n_{\theta}=6$ are used.

The change in temperature $\Delta T[\mathrm{~K}]$ at a monitoring point that has a radial distance $r[\mathrm{~m}]$ away from an ILS of a constant heat flux $q$ $[\mathrm{W} / \mathrm{m}]$ after time $t[\mathrm{~s}]$ in a medium with thermal conductivity $\lambda$ $[\mathrm{W} /(\mathrm{m} \mathrm{K})]$ and thermal diffusivity $\alpha\left[\mathrm{m}^{2} / \mathrm{s}\right]$ (i.e. the ratio between thermal conductivity and volumetric heat capacity) can be given by the ILS solution, which was initially proposed by Carslaw and Jaeger (1959).

15. 
A practical heat of hydration model for concrete curing for geotechnical

applications

Liu, Taborda, Fisher and Bourne-Webb

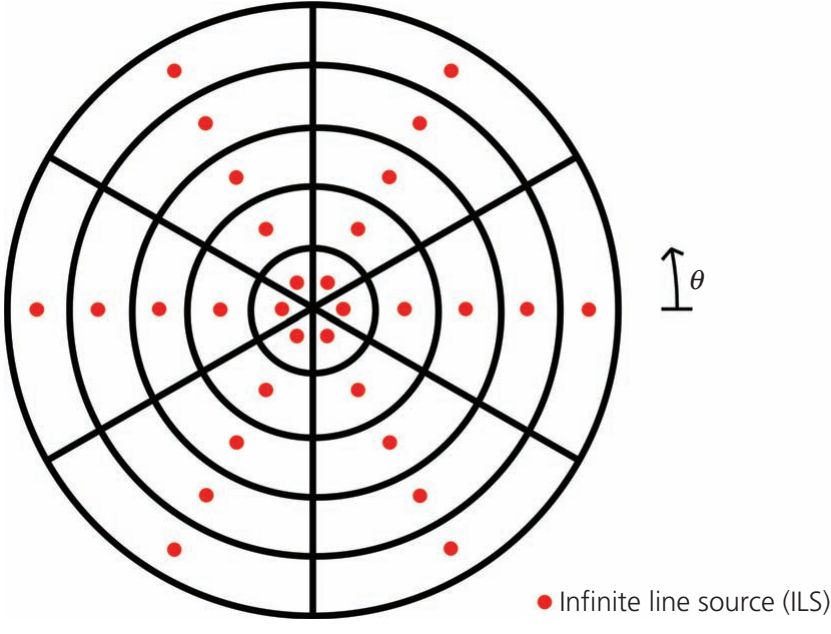

Figure 8. Illustration of the discretisation of the pile cross-section into ILSs adopted by the numerical tool for the case of $n_{\mathrm{r}}=5$ and $n_{\theta}=6$

Due to the linearity of the ILS solution, the change in temperature at a point due to multiple ILSs can be determined by adding the contribution from each ILS (i.e. the principle of superposition applies). However, Equation 15 only provides a solution due to a constant heat flux. In effect, for a heat flux that varies with time, which is the case for the heat of hydration power (Equation 10), discretisation in time is required and temporal superposition (Yavuzturk and Spitler, 1999) of the ILS solution has to be employed.

The nonlinearity of the heat of hydration model means that the temperature at each location of an ILS needs to be calculated at each time instant to be able to determine the corresponding heat of hydration power at that location. Moreover, to establish the temperature rise at a given radius (measured from the centre of the pile), which should be an axisymmetric quantity, the temperatures at an arc of points with a centre coinciding with that of the centre of the pile and spanning from $\theta=0^{\circ}$ to $180^{\circ} / n_{\theta}$ are determined and averaged. A parametric study has shown that a radial discretisation of $n_{r}=10$ and an angular discretisation of $n_{\theta}=12$ is sufficient to yield accurate results.

\section{Appendix 2}

\section{A genetic algorithm technique to calibrate model} parameters for a boundary value problem

To calibrate the model parameters $Q_{\max }, \tau$ and $\beta$ such that the simulated temperature rise from the nonlinear boundary value problem of a hydrating concrete pile matches that measured in the field, a genetic algorithm technique (Azeiteiro et al., 2009; Taborda, 2011), which is an optimisation technique inspired in natural selection, is adopted.

In this procedure, an 'individual' is made up of one set of randomly generated (within a reasonable predefined range) model parameters $\left(Q_{\max }, \tau\right.$ and $\beta$ ). A predefined number of individuals (48 is adopted in this case) then constitute a 'population'. A simulation is conducted (using the numerical technique outlined in Appendix 1 in this case) for each of the individuals, with the results compared with those measured in the field to obtain a measure of error (sum of squares of the differences in temperature rise is adopted in this case). After the simulations, each individual within the population is associated with an error, which marks the end of a generation, with individuals with smaller errors representing a better calibration for simulating the chosen problem.

Before entering the next generation, a new population has to be determined. The new population is made up of the best individuals from the old population (the best $25 \%$ of the old population are used in this case), completely new randomly generated individuals (which constitutes $25 \%$ of the new population in this case) and combining ('crossing') the best and newly generated individuals ('parent') to produce new individuals ('offspring') (which constitutes $50 \%$ of the new population in this case). During the crossing process, the parents are randomly assigned into groups of two to produce the offspring. In the current case, a constant probability crossing scheme (Taborda, 2011) is adopted, in which the decision of which parent can transfer each parameter to the offspring is independent and has a probability of $50 \%$. Moreover, during the crossing process, a 'mutation' scheme is adopted to improve the global quality of the new population, in which each parameter passed to the offspring suffers a random adjustment which is determined by the following equation (Taborda, 2011):

$$
\text { 16. } \Delta=\Delta_{\max } \times \tan \left(\frac{\pi}{2} \times\left(\frac{1}{2}+4\left(X_{\text {rand }}-\frac{1}{2}\right)^{3}\right)-\frac{\pi}{4}\right)
$$

where $\Delta$ is the mutation factor, $\Delta_{\max }$ is the maximum mutation factor ( $10 \%$ is adopted in this case) and $X_{\text {rand }}$ is a random number between 0 and 1 . Having formed a new population, the algorithm performs a new simulation of the boundary value problem for each individual, repeating all the operations outlined above. The genetic algorithm can be terminated when certain predefined stopping criteria are met (in this case, the sum of errors of the best $25 \%$ of the population does not reduce by more than $1 \%$ in 50 iterations), and the best individual gives the optimal set of parameters.

\section{REFERENCES}

Azeiteiro RN, Coelho PALF, Taborda DMG, Pedro A and Antunes D (2009) Computational study of the performance of a genetic algorithms-based software. Proceedings of COMGEO I, Juan-les-Pins, France, p. 9.

Bentz DP, Garboczi EJ, Haecker CJ and Jensen OM (1999) Effects of cement particle size distribution on performance properties of portland cement-based materials. Cement and Concrete Research 29(10) $1663-1671$.

Bentz DP, Peltz MA and Winpigler J (2009) Early-age properties of cement-based materials. II: influence of water-to-cement ratio. Journal of Materials in Civil Engineering 38(2): 512-517.

Burg RG and Ost BW (1994) Engineering Properties of Commercially Available High-Strength Concretes (Including Three-Year Data). Portland Cement Association, Skokie, IL, USA, RD104. 
Carlson RW and Forbrich LR (1938) Correlation of methods for measuring heat of hydration of cement. Industrial \& Engineering Chemistry Analytical Edition 10(7): 382-386.

Carslaw HS and Jaeger JC (1959) Conduction of Heat in Solids. Clarendon Press, Oxford, UK

Copeland LE, Kantro DL and Verbeck G (1960) Chemistry of Hydration of Portland Cement. Portland Cement Association, Skokie, IL, USA, RX153.

D'Aloia L and Chanvillard G (2002) Determining the "apparent" activation energy of concrete: $E_{\mathrm{a}}$-numerical simulations of the heat of hydration of cement. Cement and Concrete Research 32(8): 1277-1289.

Headon J, Banks D, Waters A and Robinson VK (2009) Regional distribution of ground temperature in the chalk aquifer of London, UK. Quarterly Journal of Engineering Geology and Hydrogeology 42(3): 313-323.

Johnson KR (2016) Advancements in Thermal Integrity Profiling Data Analysis. PhD thesis, University of South Florida, Tampa, FL, USA.

Kavanaugh SP and Rafferty KD (2014) Geothermal Heating and Cooling: Design of Ground-Source Heat Pump Systems. ASHRAE, Atlanta, GA, USA.

Kishi T and Maekawa K (1995) Multi-component model for hydration heat of portland cement. Concrete Library of JSCE 29(526): 97-109.

Kishi T and Maekawa K (1997) Multi-component model for hydration heating of blended cement with blast furnace slag and fly ash. Concrete Library of JSCE 30: 125-139.

Liou DD (1999) Thermal effects in large-sized diaphragm wall. Journal of Performance of Constructed Facilities 13(1): 17-21.

Loveridge F, Powrie W and Nicholson D (2014) Comparison of two different models for pile thermal response test interpretation. Acta Geotechnica 9(3): 367-384

Odler I (1998) Hydration, setting and hardening of Portland cement. In Lea's Chemistry of Cement and Concrete, 4th edn (Hewlett PC (ed.)). Elsevier, Amsterdam, the Netherlands, pp. 241-297.

Portland Cement Association (1997) Portland cement, concrete, and heat of hydration. Concrete Technology Today 18(2): 1-4
Sajadi SS (2020) Thermal Behaviour Due to Heat of Hydration of Massive Concrete Underground Structures. MSc thesis, Imperial College London, London, UK.

Scanlon JM and McDonald JE (1994) “Thermal Properties" Significance of Tests and Properties of Concrete and Concrete-Making Materials. ASTM International, West Conshohocken, PA, USA.

Schindler AK and Folliard KJ (2005) Heat of hydration models for cementitious materials. ACI Materials Journal 102(1): 24-33.

Sedaghat A, Zayed A and Sandberg P (2013) Measurement and prediction of heat of hydration of portland cement using isothermal conduction calorimetry. Journal of Testing and Evaluation 41(6): 943-950.

Sedaghat A, Shanahan N and Zayed A (2015) Predicting one-day, threeday, and seven-day heat of hydration of portland cement. Journal of Materials in Civil Engineering 27(9): 04014257.

Swaddiwudhipong S, Chen D and Zhang M (2002) Simulation of the exothermic hydration process of portland cement. Advances in Cement Research 14(2): 61-69.

Taborda DMG (2011) Development of Constitutive Models for Application in Soil Dynamics. PhD thesis, Imperial College London, London, UK.

Thomas JJ (2012) The Instantaneous apparent activation energy of cement hydration measured using a novel calorimetry-based method. Journal of the American Ceramic Society 95(10): 3291-3296.

van Breugel K (1991) Simulation of Hydration and Formation of Structure in Hardening Cement-Based Materials. Delft University Press, Delft, the Netherlands.

Wadsö L (2003) An Experimental Comparison between Isothermal Calorimetry, Semi-Adiabatic Calorimetry and Solution Calorimetry for the Study of Cement Hydration. Nordtest, Espoo, Finland, TR 522.

Yavuzturk C and Spitler JD (1999) A short time step response factor model for vertical ground loop heat exchangers. ASHRAE Transactions 105(2): 475-485.

Zayed A, Sedaghat A and Shanahan N (2013) Effects of Portland Cement Particle Size on Heat of Hydration. University of South Florida, Tampa, FL, USA.

\section{How can you contribute?}

To discuss this paper, please submit up to 500 words to the editor at journals@ice.org.uk. Your contribution will be forwarded to the author(s) for a reply and, if considered appropriate by the editorial board, it will be published as a discussion in a future issue of the journal. 